\title{
THE INHIBITION OF TRYPTIC DIGESTION OF CARTILAGE BY SYNOVIAL FLUID FROM PATIENTS WITH VARIOUS \\ TYPES OF ARTHRITIS ${ }^{1}$
}

\author{
By CHESTER S. KEEFER, WILLIAM F. HOLMES, JR, AND WALTER K. MYERS \\ (From the Thorndike Memorial Laboratory, Second and Fourth Medical Services (Harvard), \\ Boston City Hospital and the Department of Medicine, Harvard Medical School, Boston)
}

(Received for publication September 18, 1934)

In a previous paper we (1) demonstrated that some samples of synovial fluid from patients with various types of arthritis possessed the power of inhibiting the action of trypsin, when casein or the protein in the synovial fluid was used as a substrate. It was found further that this property of synovial fluid varied in different cases and the variation was dependent upon two factors: (1) the amount of free proteolytic ferment present in the fluid, (2) the variation of the inhibiting power of the fluid from case to case. The latter seemed to be of about the same degree as the anti-tryptic power of the blood plasma and the former was dependent, to some extent at least, on the number of polymorphonuclear leukocytes in the fluid.

Stimulated by our observations that synovial fluid contains anti-tryptic substances, we have carried out experiments to determine whether synovial fluid obtained from cases of arthritis is capable of inhibiting the tryptic digestion of cartilage.

\section{The digestion of cartilage with leukocytic autolysate}

The ability of leukocytic autolysate to digest cartilage was tested and the results are given in Table I.

Preparation of leukocytic autolysates and method of experiment: Leukocytes from both pneumococcal and staphylococcal exudates were used, and the autolysates were prepared in accordance with the method described by Nye (2). Portions of lung from a case of pneumococcus lobar pneumonia in the stage of grey hepatization were ground in a meat chopper containing a nut butter cutter attachment and kept in the ice box several weeks following the addition of chloroform and toluene. The lung mash was washed

1 This investigation was aided in part by a grant from the Proctor Fund of the Harvard Medical School for the Study of Chronic Diseases. through fine sterile gauze with 0.85 per cent sterile salt solution and the washings were centrifuged and washed four times with salt solution. The final volume of "cells" was diluted three times with salt solution.

In preparing the leukocytic autolysate from an exudate caused by staphylococcal infection the following method was used. A purulent exudate was obtained from the pleural cavity of a patient with staphylococcal empyema. The leukocytes were separated from the fluid by centrifuging and placed in the ice box with chloroform and toluene for two weeks. The cells were washed four times with 0.85 per cent salt solution and then diluted three times as in the preparation of the leukocytic autolysate from pneumococcal exudates.

Small pieces of cartilage were placed in flasks containing $2 \mathrm{cc}$. of leukocytic autolysate which had been adjusted to $\mathrm{pH} 4,5,6,7$ and 8 , respectively, with standard buffer solution. Two sets of five flasks each were made up in this way. One set was placed in a water bath at $37^{\circ} \mathrm{C}$. and the other at $56^{\circ} \mathrm{C}$. Cartilage and buffer solutions without leukocytic autolysate were used as controls. It had been found previously that the leukocytic autolysate contained proteolytic ferment inasmuch as it was capable of digesting coagulated blood serum.

When the flasks containing cartilage were placed in the water bath at $56^{\circ} \mathrm{C}$. with leukocytic autolysate there was complete digestion after 10 days; whereas those incubated at $37^{\circ} \mathrm{C}$. showed no visible evidence of digestion of the cartilage. As the piece of cartilage used was small, it was difficult to determine whether some digestion which could not be detected grossly had taken place or not. Therefore, in another group of experiments the cartilage was weighed under water before and after being incubated with leukocytic autolysate at $37^{\circ} \mathrm{C}$. The results, summarized in 
TABLE I

Results of incubating leukocytic autolysate and cartilage at $56^{\circ} \mathrm{C}$.

\begin{tabular}{|c|c|c|c|c|c|c|}
\hline & $\underset{4}{\mathrm{pH}}$ & $\mathrm{p}_{5}^{\mathrm{H}}$ & $\underset{6}{\mathrm{pH}}$ & $\mathrm{pH}_{7}$ & $\mathrm{p}_{8} \mathrm{H}$ & \\
\hline Leukocytic autolysate, $c c \ldots \ldots \ldots \ldots \ldots$ & 2 & 2 & 2 & 2 & 2 & 0 \\
\hline 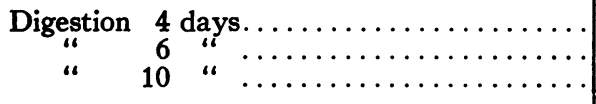 & $\begin{array}{c}0 \\
0 \\
+++\end{array}$ & $\begin{array}{c}0 \\
0 \\
+++\end{array}$ & $\stackrel{0}{++}++$ & $\begin{array}{c}0 \\
++ \\
+++\end{array}$ & $\begin{array}{c}0 \\
++++ \\
+++\end{array}$ & $\begin{array}{l}0 \\
0 \\
0\end{array}$ \\
\hline
\end{tabular}

++ Incomplete digestion

++++ Complete digestion.

Results of incubating leukocytic autolysate and cartilage at $37^{\circ} \mathrm{C}$.

\begin{tabular}{|c|c|c|c|c|c|c|}
\hline & $\underset{\mathbf{4}}{\mathrm{pH}}$ & $\mathrm{pH}_{5}$ & $\underset{6}{\mathrm{pH}}$ & $\mathrm{pH}_{7}$ & $\mathrm{p}_{\mathbf{8}}$ & \\
\hline Leukocytic autolysate, $c c \ldots \ldots \ldots \ldots \ldots$ & 2 & 2 & 2 & 2 & 2 & 0 \\
\hline 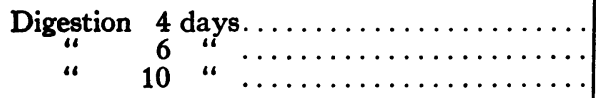 & $\begin{array}{l}\mathbf{0} \\
\mathbf{0} \\
\mathbf{0}\end{array}$ & $\begin{array}{l}\mathbf{0} \\
\mathbf{0} \\
\mathbf{0}\end{array}$ & $\begin{array}{l}0 \\
0 \\
0\end{array}$ & $\begin{array}{l}0 \\
0 \\
0\end{array}$ & $\begin{array}{l}0 \\
0 \\
0\end{array}$ & $\begin{array}{l}0 \\
0 \\
0\end{array}$ \\
\hline
\end{tabular}

Figure 1, indicate that some digestion of cartilage by leukocytic autolysate took place at $37^{\circ} \mathrm{C}$. though much less than at $56^{\circ} \mathrm{C}$.

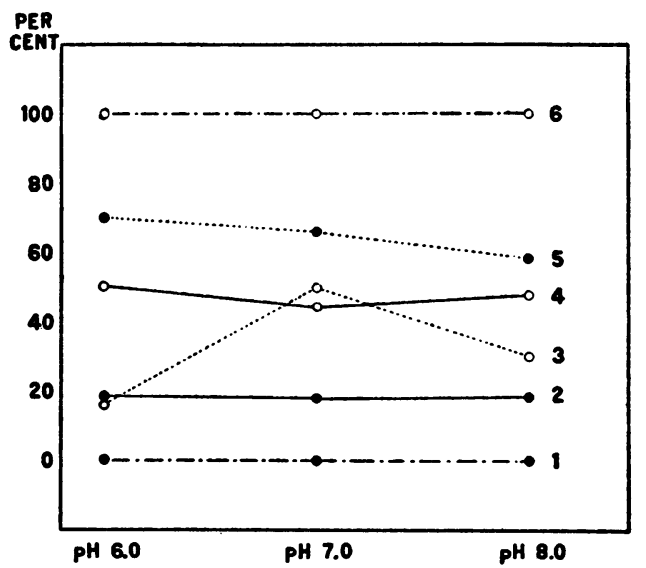

Fig. 1. Chart Illustrating the Amount of Digestion of Cartilage by Leukocytic Autolysate, at PH 6,7 AND 8 AT $37^{\circ} \mathrm{C}$. AND $56^{\circ} \mathrm{C}$.

1. Control at $37^{\circ}$ C. 2. Leukocytic autolysate from staphylococcus exudate at $37^{\circ}$ C. 3. Leukocytic autolysate from pneumococcus exudate at $37^{\circ}$ C. 4. Control at $56^{\circ}$ C. 5. Same as 2 at $56^{\circ}$ C. 6. Same as 3 at $56^{\circ} \mathrm{C}$.

The effect of synovial fluid on the digestion of - cartilage

Since leukocytic autolysate was found to contain ferments that were capable of digesting cartilage, we determined whether synovial fluid re- moved from patients with arthritis was capable of digesting cartilage or plated coagulated blood serum. The results of the study of twelve cases are recorded in Table II. Digestion of the cartilage

TABLE II

Digestion of plated blood serum and of cartilage by synovial fluid

\begin{tabular}{|c|c|c|c|c|c|c|}
\hline \multirow{2}{*}{$\underset{\text { ber }}{\text { Case }}$} & \multirow[t]{2}{*}{ Type of arthritis } & \multirow{2}{*}{$\begin{array}{c}\text { Cells } \\
\text { per } \\
\text { c. mm. }\end{array}$} & \multicolumn{2}{|c|}{$\begin{array}{l}\text { Digestion } \\
\text { of plated } \\
\text { blood } \\
\text { serum }\end{array}$} & \multicolumn{2}{|c|}{$\begin{array}{l}\text { Digestion of } \\
\text { cartilage }\end{array}$} \\
\hline & & & $37^{\circ} \mathrm{C}$. & $56^{\circ} \mathrm{C}$. & $37^{\circ} \mathrm{C}$. & $56^{\circ} \mathrm{C}$. \\
\hline $\begin{array}{r}1 \\
2 \\
3 \\
4 \\
5 \\
6 \\
7 \\
8 \\
9 \\
10\end{array}$ & $\begin{array}{c}\text { Gonococcal } \\
\text { “ } \\
\text { “ } \\
\text { “ } \\
\text { Tuberculous } \\
\text { “ }\end{array}$ & $\begin{array}{r}9,750 \\
7,850 \\
10,000 \\
12,200 \\
12,250 \\
21,000 \\
15,650 \\
6,650 \\
11,600 \\
6,500\end{array}$ & $\begin{array}{l}0 \\
0 \\
0 \\
0 \\
0 \\
0 \\
0 \\
0 \\
0 \\
0\end{array}$ & $\begin{array}{l}0 \\
0 \\
0 \\
0 \\
0 \\
0 \\
0 \\
0 \\
0 \\
0 \\
0\end{array}$ & $\begin{array}{l}0 \\
0 \\
0 \\
0 \\
0 \\
0 \\
0 \\
0 \\
0 \\
0\end{array}$ & $\begin{array}{l}0 \\
0 \\
0 \\
0 \\
0 \\
0 \\
0 \\
0 \\
0 \\
0\end{array}$ \\
\hline 11 & Staphylococcal & 110,000 & + & + & \pm & $+t+t$ \\
\hline 12 & Staphylococcal & 240,000 & + & + & \pm & $+++t$ \\
\hline
\end{tabular}

was not observed in seven samples of synovial fluid from gonococcal arthritis or in three samples from tuberculous arthritis. In the two cases of staphylococcal arthritis, in which there were large numbers of polymorphonuclear leukocytes, digestion was apparent. From these experiments it 
seems that when the total cell count was low digestion of cartilage did not occur, and that this failure to digest was probably due to a lack of sufficient ferment or to the presence of antiferment in the fluid.

\section{Ferment-inhibiting action of synovial fluid}

We next studied the ferment-inhibiting action of synovial fluid when cartilage was used as a substrate and trypsin, instead of leukocytic auto-
In all, fifty-four samples of synovial fluid from forty-five cases of arthritis were studied in this way. They included twenty-three cases of gonococcal arthritis, ten cases of rheumatic fever, seven cases of rheumatoid arthritis, three cases of traumatic arthritis and one each of tuberculous and streptococcal arthritis. The results are summarized in column $A$ of Figure 2. It was found that $0.1 \mathrm{cc}$. of a 1 per cent solution of trypsin was capable of digesting the amount of cartilage used,

TABLE III

Example of experiment testing inhibiting action of synovial fluid

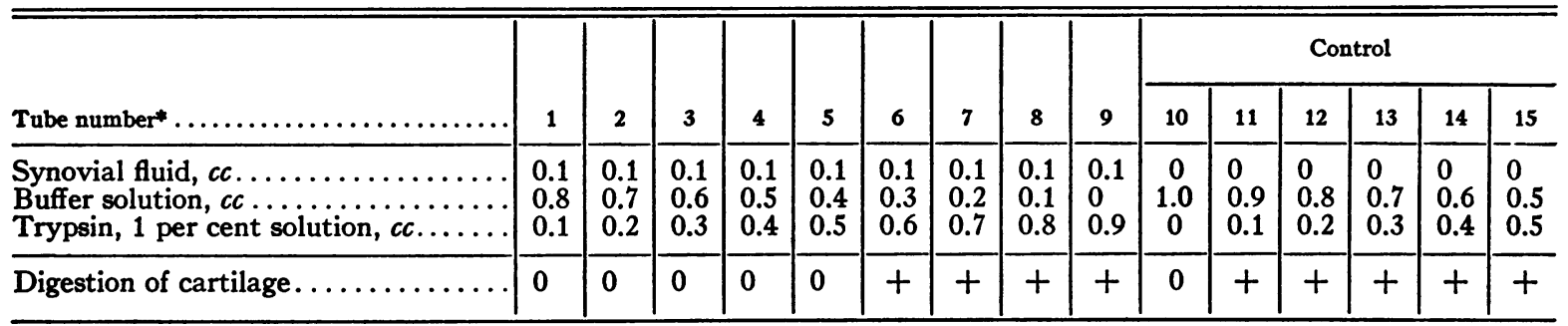

* Each tube contained a piece of cartilage of equal size.

lysate, was employed as the ferment. This was done because the action of trypsin was more prompt than that of leukocytic autolysate.

\section{MATERIALS AND METHODS}

Small rings of cartilage of approximately equal size were obtained from the trachea of rabbits. These were placed in test tubes with $0.1 \mathrm{cc}$. of synovial fluid from various patients with arthritis. To these tubes 1 per cent solution of trypsin was added in amounts varying from 0.1 to $0.9 \mathrm{cc}$. The volume of all the mixtures was made up to 1 cc. with standard buffer solution of $\mathrm{pH} 8$ and placed in the water bath at $56^{\circ} \mathrm{C}$. for twenty-four hours. As controls, trypsin in varying amounts was added to the cartilage without the synovial fluid, and cartilage in buffer solution without trypsin was incubated for a similar length of time. The amount of trypsin inhibited by $0.1 \mathrm{cc}$. of synovial fluid was determined from the tube containing the largest amount of trypsin showing no digestion of the cartilage. An example of an experiment is summarized in Table III. In this case, $0.1 \mathrm{cc}$. of synovial fluid inhibited the digestive activity of $0.5 \mathrm{cc}$. of trypsin, whereas in the control $0.1 \mathrm{cc}$. of trypsin was capable of producing complete digestion of the cartilage. so that it was obvious that synovial fluid was capable of inhibiting tryptic digestion of cartilage.

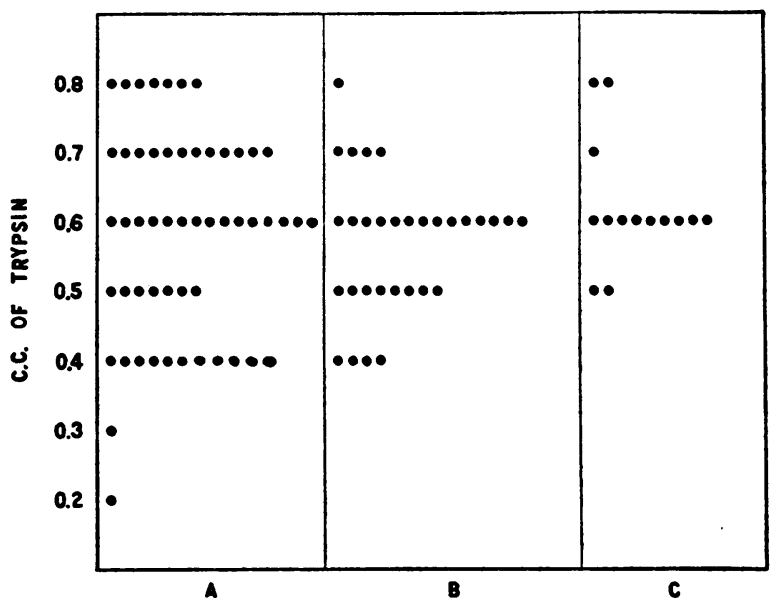

Fig. 2. Diagram Illustrating the Anti-tryptic ACtivity of Synovial Fluid and Blood Plasma When Cartilage Was Used as a Substrate.

Each dot represents the amount of trypsin inhibited by 0.1 cc. of synovial fluid or blood plasma.

$A$. Samples of synovial fluid from patients with arthritis.

$B$. Blood plasma from patients with arthritis.

C. Blood plasma from patients without arthritis.

That the anti-tryptic activity of the synovial fluid was not reduced by bacteria, such as hemo- 
lytic streptococci, growing in it was shown by the following experiments. Hemolytic streptococci were added in large numbers to twelve samples of synovial fluid and grown at a temperature of $37^{\circ} \mathrm{C}$. for twenty-four hours; then the synovial fluid was added to the trypsin and cartilage as in the previous experiments. The results were the same for infected as for non-infected fluids.

TABLE IV

Comparison of inhibitory action of infected and non-infected synovial fluid

$\begin{array}{ccc}\begin{array}{c}\text { Number } \\ \text { of } \\ \text { cases }\end{array} & \begin{array}{c}\text { Amount of } \\ \text { trypsin inhibited by } \\ \text { 0.1 cc. of synovial fluid }\end{array} & \begin{array}{c}\text { Amount of trypsin } \\ \text { inhibited by } 0.1 \text { cc. of } \\ \text { infected synovial fluid }\end{array} \\ 1 & c c . & c c . \\ 8 & 0.5 & 0.5 \\ 2 & 0.6 & 0.6 \\ 1 & 0.7 & 0.7 \\ 12 & 0.8 & 0.8\end{array}$

Comparison of anti-tryptic activity of blood plasma and synovial fluid

It would be surprising if the synovial fluid and the blood plasma did not contain similar amounts of anti-tryptic activity, since synovial fluid is an exudation of blood plasma together with a collection of leukocytes derived from the circulating blood, and cells and mucin derived from the synovial membrane itself. To compare the ability of the blood plasma to inhibit the digestion of cartilage with that of synovial fluid, forty-five samples of blood plasma were studied in the same way as the synovial fluid. The results are charted in Figure 2. The ability of blood plasma to inhibit the digestive action of trypsin when cartilage was used as a substrate was the same as that of synovial fluid, and the variations in the anti-tryptic substances of the blood plasma in patients without arthritis were as great as those with disease of the joints.

\section{Relation of cell count of synovial fluid to anti-tryptic activity}

In the experiments (1) in which the anti-tryptic activity of synovial fluid was studied, using casein or the protein of the synovial fluid as a substrate, it was found that it was more common to have diminished anti-tryptic activity when the fluid contained large numbers of leukocytes than when they were present in small numbers. Figure 3 was constructed to demonstrate the lack of correlation between the total cell count and the anti-tryptic activity. At first glance, these observations seem to be in conflict with our previous experiments mentioned above and they require comment. From the experiments summarized in Table II, there could be no doubt that synovial fluid containing large numbers of leukocytes $(110,000$ and

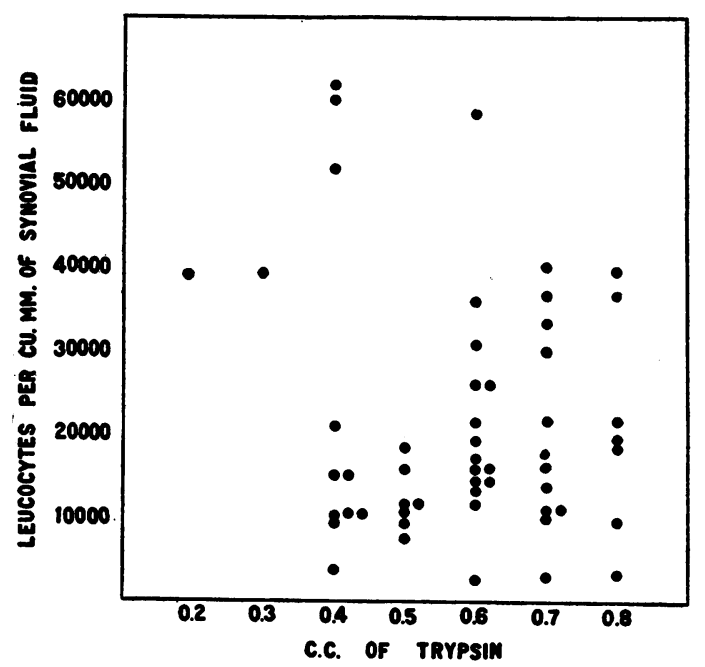

Fig. 3. Diagram Showing the Variation of the ANTI-TRYPTic Activity and the Total Number of Leukocytes in the Synovial Fluid.

Each dot represents the number of leukocytes in 1 c.mm. of synovial fluid and the amount of trypsin the synovial fluid was capable of inhibiting when cartilage was used as a substrate.

$240,000)$ per cubic centimeter was capable of digesting cartilage, whereas those with few leukocytes were not. In the experiments recorded in Figure 3 there were no samples of synovial fluid containing more than 60,000 leukocytes per cubic centimeter and most of them were under 20,000 per cubic centimeter. It seems reasonable to assume, then, that the ferment derived from the leukocytes in the cases studied was not sufficient to enhance the action of the trypsin or decrease the anti-tryptic activity of the synovial fluid which might occur independent of the leukocyte count. It appears, therefore, that cartilage may be protected from the activity of tryptic ferments even in the presence of large numbers of leukocytes. When they become excessive, however, the ferment action predominates and cartilage is destroyed. There was no correlation between the 
type of arthritis and the anti-tryptic content of the synovial fluid in our cases.

\section{DISCUSSION}

From these observations one may conclude that synovial fluid exhibits as much anti-tryptic activity as blood plasma, and that the anti-ferment of synovial fluid is most likely acquired from the blood plasma by exudation of fluid into the joint cavity. Moreover, since anti-tryptic substances were not destroyed by bacteria but were shown to be less active in the presence of an excess of ferment or leukocytic autolysate, it seems reasonable to postulate that when exudates occur in joints the extent of the damage will depend in part upon the excess of ferment over anti-ferment.

Phemister (3) has pointed out that purulent exudates containing polymorphonuclear cells in abundance are capable of digesting small pieces of cartilage and he attributes this to proteolytic ferments from the cells. He showed further that exudates obtained from tuberculous lesions were incapable of digesting cartilage. This he attributed to a lack of proteolytic ferment from cells which he reported were predominately monocytes and lymphocytes. From his observations and from the fact that purulent exudation into joints is often followed by destruction of cartilage, and from the evidence that tuberculous infection is followed by less digestion of cartilage than occurs in other types of arthritis, Phemister concluded that the type of cellular response was important in deciding whether or not extensive destruction of cartilage will take place. Our observations are in complete agreement with his. It is necessary, however, to take into consideration the presence of anti-tryptic substances as well as the presence of ferments in any given case. We feel that one of the reasons that destruction takes place in one case of acute joint infection and not in all cases of the same kind is that only in some cases are anti-ferment substances not in excess of the ferments. This anti-tryptic activity, when it is present, limits the destruction of tissue; it can, however, be overcome by a great excess of ferment.

\section{SUMMARY AND CONCLUSIONS}

1. Synovial fluid from patients with arthritis of various types inhibits, in the test tube, the digestion of cartilage.

2. This property is not destroyed by growing hemolytic streptococci in the synovial fluid.

3. Leukocytic autolysates digest cartilage in vitro, especially at $56^{\circ} \mathrm{C}$. This action can be inhibited by synovial fluid.

4. The presence of large amounts of antitryptic substances in synovial fluid probably prevents or limits the destruction of cartilage by the enzymes liberated in purulent exudates.

\section{BIBLIOGRAPHY}

1. Holmes, W. F., Jr., Keefer, C. S., and Myers, W. K., Anti-tryptic activity of synovial fluid in patients with various types of arthritis. J. Clin. Invest., $1935,14,124$.

2. Nye, R. N., Studies on the pneumonic exudate. V. The relation of pneumonic lung protease activity to hydrogen ion concentration, and a consideration of the origin of the enzyme. J. Exper. Med., 1922, 35,153 .

3. Phemister, D. B., The effect of pressure on articular surfaces in pyogenic and tuberculous arthritides and its bearing on treatment. Ann. Surg., 1924, 80, 481. 